\title{
APLICAÇÃO DE ADSORVENTE NATURAL UTILIZANDO METODOLOGIAS ANALÍTICAS PARA “CLEAN-UP” DE ÁGUAS SUBTERRÂNEAS
}

\author{
Ana Maria de Souza Araújo ${ }^{1}$, Francisco Carlos de Medeiros Filho², \\ Denise Domingos da Silva ${ }^{3}$
}

${ }^{1}$ Curso de Licenciatura em Química, Unidade Acadêmica de Biologia e Química, Universidade Federal de Campina Grande, Laboratório de Biocombustíveis e Química Ambiental, Cuité-PB, Brasil.

${ }^{2}$ Curso de Ciências Naturais e Biotecnologias, Programa de Pós-Graduação Ciências Naturais e Biotecnolgias, Universidade Federal de Campina Grande, Laboratório de Biocombustíveis e Química Ambiental, Cuité-PB, Brasil.

${ }^{3}$ Prof ${ }^{a}$ Unidade Acadêmica de Biologia e Química, Universidade Federal de Campina Grande, Laboratório de Biocombustíveis e Química Ambiental, Cuité-PB, Brasil.

E-mail para correspondência: dedomingos@gmail.com

\section{Resumo}

Como a água é um meio necessário para a sobrevivência dos seres vivos, é essencial que se tenha controle em relação à sua qualidade. No nordeste brasileiro, a escassez vem impedindo o desenvolvimento e sobrevivência dos habitantes. Com isso, a população têm utilizado águas subterrâneas para suprir suas necessidades, logo suas análises são de vital importância devido estas águas não passarem por nenhum tipo de tratamento antes de serem utilizadas, como acontece no município de Baraúna-Paraíba. Objetivou-se determinar algumas propriedades físico-químicas de águas subterrâneas do município de Baraúna-Paraíba, além de utilizar a cortiça como adsorvente natural para tratamento das amostras. Foram realizadas medições de $\mathrm{pH}$, turbidez, condutividade elétrica, dureza, alcalinidade, sólidos totais dissolvidos, teor de cloreto e concentração de sódio e potássio. Além disso, foi analisado no Espectrômetro de Fluorescência de Raios-X por Energia Dispersiva-EDX a composição química da cortiça in natura e após o tratamento. Dentre os parâmetros analisados neste estudo antes e após a adsorção, apenas os valores obtidos na concentração de sódio não estão de acordo com o valor máximo permitido pela Portaria de Consolidação № 5/2017 do Ministério da Saúde, caracterizando as amostras como imprópria para o consumo da população.

Palavras-chave: adsorção, águas subterrâneas, cortiça.

\section{Abstract}

As water is a necessary means for living beings survival, it is essential to have control over its quality. In the northeast of Brazil, scarcity has been impeding the 
development and survival of the inhabitants. As a result, the population has been using groundwater to supply their needs, so its analysis are vitally important because water does not undergo any type of treatment before being used, as in the city of Baraúna-Paraíba. The objective is to determine some physicochemical substances from groundwater in the city of Baraúna-Paraíba, besides using cork water as a natural adsorbent for the treatment of samples. Measurements of $\mathrm{pH}$, turbidity, electrical conductivity, hardness, alkalinity, total dissolved solids, chloride content and sodium and potassium concentration were performed. In addition, the chemical composition of cork in natura and after treatment was analyzed on the Xray Fluorescence Spectrometry Dispersive Energy-EDXRF. Among the parameters analyzed in this study before and after adsorption, only the values obtained in the sodium concentration are not in accordance with the maximum allowed by Consolidation Ordinance in Law 5/2017 of the Ministry of Health, characterizing the samples as improper for people consumption.

Keywords: absorption. groundwater. cork water.

\section{Introdução}

Sendo a água uma substância necessária para a sobrevivência dos seres vivos, é essencial que se tenha controle em relação a sua qualidade. Cabendo destacar que mesmo que o planeta Terra em grande parte seja constituído por água, a dificuldade de encontrar águas naturais adequadas para o consumo humano é grande.

A água cobre cerca de $70 \%$ da superfície da Terra. Mais de $97 \%$ da água do planeta são águas salgadas e estão nos oceanos e mares. Não serve nem para uso industrial. A água doce representa apenas $3 \%$ da água total, cerca de $2 \%$ da água doce estão congeladas nos círculos polares, os quais cobrem $10 \%$ da superfície da Terra, e somente $0,6 \%$ da água doce está disponível diretamente para o consumo humano. Destes $0,6 \%, 97 \%$ correspondem a águas subterrâneas e apenas 3\% apresentam-se na forma de água superficial nos lagos e rios de extração mais fácil. (MENEZES et al., 2011, p.2)

No nordeste brasileiro, em especial na região do semiárido, a disponibilidade de água têm se tornado cada vez mais limitada. Sendo assim, a escassez tem impedido tanto o desenvolvimento como a sobrevivência dos seres que habitam esta região. Segundo Medeiros (2016), o uso irracional e contaminação da água, a supressão de vegetação e manejo inadequado do solo tem contribuído para aumentar a escassez pelo mundo, inclusive no Brasil.

Nessa concepção, a população para reparar esta problemática da água e suprir suas necessidades vem utilizando águas subterrâneas, devido em alguns lugares elas serem mais abundantes, como acontece no município de Baraúna-Paraíba, que tornou-se a área de estudo. De acordo com os dados do 
IBGE (2010), o município de Baraúna-Paraíba apresenta uma densidade demográfica de $83,43 \mathrm{hab} / \mathrm{km}^{2}$.

De acordo com Costa et al. (2012), águas subterrâneas são de extrema importância, principalmente como reservatório de água doce que se encontra disponível para os seres vivos. Considerando que mais de $60 \%$ da população mundial tem como principal fonte de águas de lençóis freáticos e subterrâneos.

Entretanto, não basta apenas suprir essa necessidade do abastecimento hídrico, é necessário que a população utilize águas de qualidade e que não provoque danos na sua saúde. Porém, percebe-se que a maioria das águas subterrâneas antes de serem utilizadas não passam por nenhum tipo de tratamento ou análise, tornando-se assim evidente o surgimento de danos na saúde dos seres humanos que a utilizam.

Sendo assim, com o intuito de melhorar a qualidade das águas, removendo metais tóxicos e outros materiais, tem-se procurado por novas metodologias que possam auxiliar nesse processo de tratamento e que atendam esta demanda de maneira significativa. Diante disso, objetivou-se determinar algumas propriedades físico-químicas de águas subterrâneas do município de Baraúna-Paraíba, além de utilizar a cortiça como adsorvente natural para tratamento das amostras.

\section{Metodologia}

\subsection{Amostragem e coleta das amostras}

Em um levantamento realizado no município de Baraúna-Paraíba registrou-se a existência de 14 pontos de água, sendo 06 poços escavados e 08 poços tubulares (BRASIL, 2005). Entretanto, para o desenvolvimento da pesquisa foram selecionados 4 poços subterrâneos que estão situados na zona urbana do município de Baraúna-Paraíba e são identificados de poço $A, B, C$ e D. Foram coletadas 3 amostras de cada ponto identificadas e armazenadas em garrafas de politereftalato de etileno (PET) com capacidade de 2,0 litros previamente higienizadas, preenchidas por completo e mantidas em refrigeração até a análise, com 0 intuito de evitar alterações nas características. As amostras foram coletadas por estudantes do curso de química da Universidade Federal de Campina Grande, Campus Cuité/Paraiba, no mês de setembro de 2018. A tabela 1 informa a localização exata dos 
poços, enquanto a figura 1 apresenta a marcação dos pontos no mapa da cidade.

Tabela 1: Localidades dos poços.

\begin{tabular}{|c|c|}
\hline Amostras & Localidades \\
\hline A & Rua da Independência \\
\hline B & Rua Nazário Cassiano de Oliveira \\
\hline C & Rua Padre Cícero \\
\hline D & Rua Francisco Italiano \\
\hline & Fonte: Dados da pesquisa, 2019. \\
\hline
\end{tabular}

Figura 1: Localização das amostras no mapa de Baraúna.

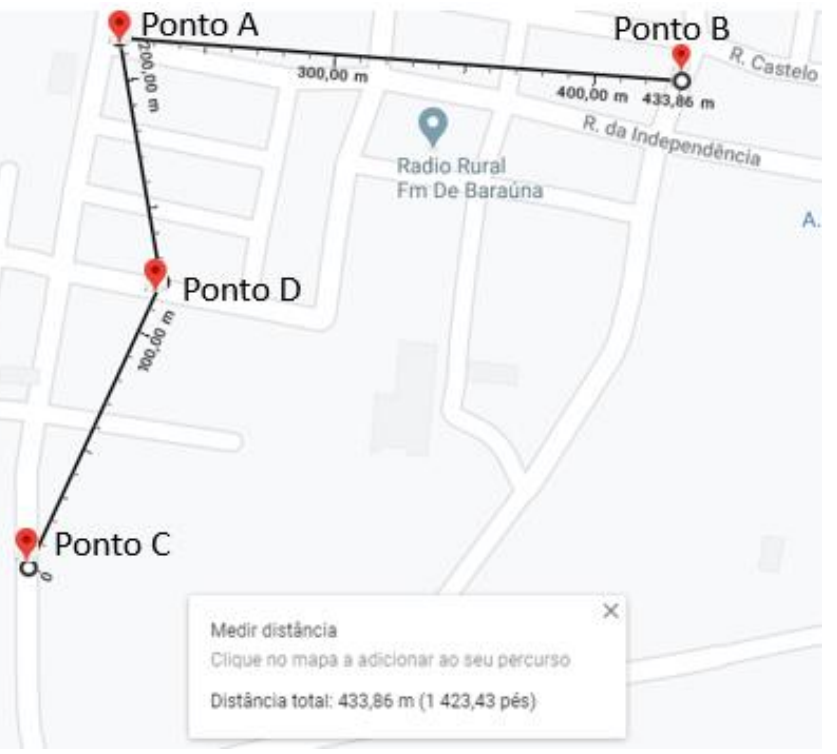

Fonte: Google Maps (adaptado), 2020.

\subsection{Determinação de propriedades físico-químicas das amostras}

Quanto a determinação de propriedades Físico-Químicas, as análises das amostras foram realizadas em triplicata no laboratório de Biocombustíveis e Química Ambiental da Universidade Federal de Campina Grande/Cuité-PB e seguiu-se de metodologias recomendadas pelo manual prático de análise de água da Fundação Nacional da Saúde (FUNASA, 2013) e do Standard Methods for the Examination of Water and Wastewater (APHA, 2012).

\subsection{Potencial hidrogeniônico $(\mathrm{pH})$}

Para determinação das medidas de potencial Hidrogênico $(\mathrm{pH})$ foi utilizado um peagâmetro $\mathrm{pH}$ 21-Hanna, sendo previamente calibrado com soluções tampão ácido de 4,01 \pm 0,01 e básico de 7,01 \pm 0,01 (APHA, 2012). 


\subsection{Turbidez}

Já o parâmetro de Turbidez foi determinado por um turbidímetro modelo TB1000, calibrado com soluções padrões de 0,1 NTU, 0,8 NTU, 8 NTU, 80 NTU e 1000 NTU (APHA, 2012).

\subsection{Condutividade Elétrica}

A Condutividade Elétrica foi determinada utilizando um condutivímetro $M S$ Tecnopon, previamente calibrado com uma solução padrão de cloreto de potássio $(\mathrm{KCl}) 146,9 \mu \mathrm{S} / \mathrm{cm}$ a uma temperatura padronizada de $25^{\circ} \mathrm{C}(\mathrm{APHA}$, 2012).

\subsection{Dureza}

Para determinação da Dureza foi utilizado o método clássico de volumetria de complexação utilizando como agente titulante o EDTA (ácido etilenodiaminotetracético) com a concentração de 0,01 mol.L $\mathrm{L}^{-1}$ e como indicador o negro de Eriocromo - T (NET) com pH 9,4 (APHA,2012).

\subsection{Alcalinidade}

As medidas de Alcalinidade foram realizadas pelo método de volumetria de neutralização com ácido sulfúrico $0,02 \mathrm{M}$ como agente titulante e solução indicadora alaranjado de metila 0,1 mol.L-1 (FUNASA, 2013).

\subsection{Cloretos}

$\mathrm{Na}$ determinação de Cloretos foi utilizado a volumetria de precipitação com Nitrato de Prata 0,1 mol.L-1 pelo método de Mohr, e como indicador o Cromato de Potássio 0,1 mol.L-1 (FUNASA, 2013).

\subsection{Concentração de potássio e sódio no fotômetro de chama}

Em relação a Concentação dos cátions metálicos Potássio $\left(\mathrm{K}^{+}\right)$e Sódio $\left(\mathrm{Na}^{+}\right)$ foi utilizado um fotômetro de chama QUIMIS Q498M. O aparelho foi calibrado com soluções padrão de 100 ppm de $\mathrm{Na}^{+}$e $\mathrm{K}^{+}$. Em seguida as amostras de águas foram analisadas com as respectivas concentrações e determinando a coloração da chama específica de cada substância (QUIMIS, 2011). 


\subsection{Sólidos Totais Dissolvidos}

Em relação aos Sólidos Totais Dissolvidos, inicialmente, lavou-se previamente a cápsula de porcelana, depois, a aqueceu por uma hora em uma estufa a $105^{\circ} \mathrm{C}$, após este tempo, retirou-se a cápsula, resfriando-a até a temperatura ambiente em um dessecador. Após atingir a temperatura ambiente, pesou-se a cápsula anotando o valor referente ao seu peso. Mediu-se $100 \mathrm{~mL}$ de cada amostra em um balão volumétrico, logo, transferiu-se este volume para a cápsula previamente seca para realizar a evaporação. A evaporação na estufa, teve uma duração de duas horas, em uma temperatura entre $103-105^{\circ} \mathrm{C}$. Após a evaporação, a cápsula foi levada para o dessecador para esfriá-la. Em seguida, pesou-se novamente a cápsula contendo o resíduo seco. Todo esse processo consiste na medição entre a diferença do que se obtinha antes e depois da evaporação das amostras (APHA, 2012).

\subsection{Preparação do adsorvente}

Na Preparação do Adsorvente, a matéria prima da cortiça foi coletada a partir da rolha de cortiça que, geralmente, é descartada. As rolhas são derivadas da árvore da espécie Sobreiro (Quercus Súber). De acordo com Costa (2011), a cortiça é quimicamente constituída por vários tipos de compostos, que tradicionalmente são divididos em cinco grupos: suberina (45\%), lenhina (27\%), polissacáridos (12\%), taninos (6\%) e ceróides $(6 \%)$.

Em relação as propriedades da cortiça, Costa (2011) afirma que a cortiça apresenta: baixa densidade, elevada deformabilidade e baixa resistência à deformação, grande capacidade de absorção de energia e dissipação de energia, elevado coeficiente de atrito, baixa condutividade térmica, boa inércia química, baixa absorção de água e outros líquidos e boa resistência ao fogo.

Para a obtenção do adsorvente, o material foi cortado em pedaços menores e triturado no moinho de facas Wyllie Modelo: CE-430/Micro, até se obter uma espécie de farelo do material triturado. Em seguida, este material obtido foi pesado em uma balança analítica marca BEL ENGINEERING com $24 \mathrm{~V} \pm 550 \mathrm{~mA}$ modelo M214Ai. Posteriormente, este material foi secado em 
uma estufa de secagem modelo QUIMIS Q31711-23 com 110/220V - 1000W a $60^{\circ} \mathrm{C}$ por duas horas.

\subsection{Análise granulométrica}

$\mathrm{Na}$ Análise Granulométrica, o material foi secado em temperatura ambiente e, posteriormente, levado à estufa com a temperatura de $60^{\circ} \mathrm{C}$ por duas horas, para evitar alteração no peso da amostra devido à umidade do ambiente e aglutinação dos grãos. Esse método foi utilizado com o intuito de classificar e caracterizar a granulometria da amostra. Depois do material está seco, foi utilizado o processo de peneiramento com agitação por meio de um conjunto de sete peneiras com diferentes tipos de malhas numa máquina de Rot-up. As peneiras, apresentam intervalos de: $2 \mathrm{~mm} ; 1 \mathrm{~mm} ; 500 \mu \mathrm{m} ; 250 \mu \mathrm{m} ; 125 \mu \mathrm{m} \mathrm{e}$ $53 \mu \mathrm{m}$, caracterizando-se como: cascalho; areia muito grossa; areia média; areia fina; areia muito fina e silte, respectivamente.

\subsection{Cromatografia em coluna}

Para o tratamento das amostras foi utilizado o adsorvente natural (cortiça) com diferentes granulometria e a técnica foi à Cromatografia em Coluna em uma bureta de $25 \mathrm{~mL}$. A bureta foi preenchida aos poucos com 3,0 gramas do adsorvente natural (cortiça) para realização do empacotamento da coluna, em seguida foi previamente lavada com água destilada. Entretanto, mesmo seguindo com cautela este procedimento não foi possível realizar a cromatografia em coluna, devido a cortiça apresentar uma baixa densidade que interferiu diretamente no processo do empacotamento da coluna, tornando assim inviável a metodologia. Com isso, iniciou-se buscas por metodologias que utilizassem a cortiça como adsorvente para iniciar o tratamento das amostras, no qual optou-se por realizar a adsorção por filtração.

\subsection{Adsorção por filtração}

Para o tratamento das amostras foi utilizado o adsorvente natural (cortiça) de duas granulometrias, $250 \mu \mathrm{m}$ e $125 \mu \mathrm{m}$, respectivamente. As amostras analisadas por esta metodologia foram as amostras A e D, devido estas apresentarem os maiores e menores valores nos parâmetros analisados. As amostras de cortiça foram pesadas em uma balança analítica com medidas de 
3,0 gramas cada. Em seguida as cortiças foram colocadas em contato com água destilada passando por agitação magnética para realizar a lavagem do material, com o intuito de preparar a cortiça( adsorvente) retirando interferentes e por fim filtradas com papel filtro qualitativo.

Nas amostras das águas subterrâneas, utilizou-se $100 \mathrm{~mL}$ de cada amostra que foram colocadas em contato com o adsorvente lavado no procedimento descrito anteriormente, para realizar a agitação utilizou-se um agitador magnético modelo QUIMIS M6261-22 com 220V a 600W em seguida, as amostras foram filtradas e por fim analisou-se algumas propriedades físicoquímicas das águas após a adsorção.

\subsection{Análise da composição química da cortiça no Espectrômetro de Fluorescência de Raios-X por Energia Dispersiva-EDX}

A determinação da composição química da cortiça foi feita pela técnica de Espectrômetro de Fluorescência de Raios-X por Energia Dispersiva - EDX, utilizando um espectrômetro digital da SHIMADZU, modelo EDX-7000. Foi utilizado como padrão, um metal esférico com dimensões de comp.: $15 \mathrm{~cm}$ lar.:13 cm e alt.:14 cm que avalia o percentual de alguns elementos que 0 constitui. Em seguida, foi introduzido a amostra em micro tubos com dimensões de comp.:15 cm - lar.:13 cm e alt.:14 cm. Para que a amostra seja introduzida no tubo sem contaminação e interferências, utilizou-se um filme fino de prolypropylene 3520 transparente que reveste a parte inferior e superior do tubo, posteriormente, a amostra foi introduzida para uma leitura de 10 minutos.

\section{Resultados}

\subsection{Análise de $\mathrm{pH}$, condutividade elétrica e turbidez antes da adsorção}

De acordo com a Portaria de Consolidação do Ministério da Saúde (MS) $n^{\circ}$ 5/2017, o pH da água deve ser mantido na faixa de 6,0 a 9,5 (BRASIL, 2017). Borges; Galbiatti; Ferraudo (2003), afirma que o tipo de solo por onde a água percorre pode interferir nos valores de $\mathrm{pH}$ dos corpos d'águas.

A condutividade elétrica é determinada pela possibilidade de uma solução conduzir a passagem de corrente elétrica, isto dependendo da presença de cátions ou ânions. Quanto maior a concentração iônica da solução, maior é a oportunidade para ação eletrolítica e, portanto, maior a capacidade em conduzir corrente elétrica (APHA, 2012). 
A turbidez é um parâmetro que é definido como uma característica física de amostras de água que reduz a sua transparência à passagem de luz através do líquido.

A tabela 2 apresenta os valores médios de $\mathrm{pH}$, condutividade elétrica e turbidez obtidos no estudo realizado nos poços do município de Baraúna-PB antes da adsorção e seus respectivos desvios padrão.

Tabela 2: Valores médios de $\mathrm{pH}$, condutividade elétrica e turbidez dos poços.

\begin{tabular}{|c|c|c|c|}
\hline $\begin{array}{c}\text { Poços } \\
\text { analisados }\end{array}$ & $\begin{array}{c}\text { Valores médios de } \\
\mathbf{p H}\end{array}$ & $\begin{array}{c}\text { Condutividade elétrica } \\
(\boldsymbol{\mu S} / \mathbf{c m})\end{array}$ & Turbidez (NTU) \\
\hline Poço A & $6,08 \pm 0,020$ & $2450 \pm 0,015$ & $0,63 \pm 0,026$ \\
\hline Poço B & $6,35 \pm 0,017$ & $2520 \pm 0,000$ & $1,43 \pm 0,064$ \\
\hline Poço C & $6,62 \pm 0,020$ & $2710 \pm 0,012$ & $0,16 \pm 0,007$ \\
\hline Poço D & $6,56 \pm 0,017$ & $2710 \pm 0,012$ & $0,34 \pm 0,012$ \\
\hline VMP* & $\mathbf{6 , 0} \mathbf{9} \mathbf{9 , 5}$ & Não especificado & $\mathbf{5 , 0}$ NTU \\
\hline
\end{tabular}

Analisando a tabela 2 acima, é possível perceber que os valores médios de $\mathrm{pH}$ dos poços variam de 6,08 a 6,62, se adequando aos valores estabelecidos pelo Ministério da Saúde (BRASIL, 2017). Um estudo realizado por Santos et al. (2013) na cidade de Chiapetta-RS e Santo Antônio das Missões-RS, obteve-se uma média de pH de 6,26 entre as amostras. No que diz respeito a análise de condutividade elétrica os poços que apresentaram maiores valores foram o $B(2520 \mu \mathrm{S} / \mathrm{cm})$ e o $C(2710 \mu \mathrm{S} / \mathrm{cm})$, entretanto, não é especificado na portaria o valor máximo permitido para uma condutividade ideal.

Observando a tabela 2, percebe-se que a turbidez das amostras variam entre 0,16 e 1,43 NTU. Portanto, encontra-se de acordo com o padrão estabelecido pelo MS, onde o valor máximo é de 5,0 NTU. Segundo Santos et al. (2013), as amostras de águas subterrâneas da cidade de Chiapetta-RS e Santo Antônio das Missões-RS, obtiveram valores abaixo do permitido, obtendo-se uma média de 0,573 NTU. Em conformidade com o estudo feito por Machado et al. (2017), onde no município de Paraíso do Tocantins-TO o parâmetro turbidez das amostras subterrâneas apresentaram valores baixos, sendo o maior valor obtido de 0,15 NTU. 


\subsection{Análise de dureza, teor de cloretos, alcalinidade e sólidos totais dissolvidos antes da adsorção}

A dureza é a concentração de cátions multimetálicos em solução. Os cátions frequentemente associados à dureza são cálcio e magnésio $\left(\mathrm{Ca}^{2+}, \mathrm{Mg}^{2+}\right)$, e em menor escala ferro $\left(\mathrm{Fe}^{2+}\right)$, manganês $\left(\mathrm{Mn}^{2+}\right)$, estrôncio $\left(\mathrm{Sr}^{2+}\right)$ e alumínio $\left(\mathrm{Al}^{3+}\right)$ (Brasil, 2006). A origem da dureza das águas pode ser natural (por exemplo, dissolução de rochas calcárias, ricas em cálcio e magnésio) ou antropogênica (lançamento de efluentes industriais) (FUNASA, 2014).

Os cloretos estão distribuídos na natureza geralmente na forma de sais de sódio $(\mathrm{NaCl})$, de potássio $(\mathrm{KCl})$, e sais de cálcio $\left(\mathrm{CaCl}_{2}\right)$. A maior quantidade desses sais está presente nos oceanos (FUNASA, 2014). Além disso, o cloreto é um componente muito encontrado em análises de recursos hidrícos.

De acordo com Santos e Mohr (2014), a alcalinidade é representada pela presença de íons hidróxido, carbonato e bicarbonato. A alcalinidade é a medida da capacidade que a água tem de neutralizar ácidos, isto é, a quantidade de substâncias na água que atua como tampão, decorrente da presença de bases fortes, fracas e de sais de ácidos fracos.

Os sólidos totais dissolvidos representam todos os constituintes químicos que estão dissolvidos na água. Segundo Casali (2008), águas com excesso de STD se torna desagradável ao paladar em virtude da alteração no gosto e o consumo pode provocar o acúmulo de sais na corrente sanguínea e ocasionar a formação de cálculos renais.

A seguir, a tabela 3 apresenta os resultados das amostras analisadas ao teor da dureza, alcalinidade, cloretos e sólidos totais dissolvidos (STD) incluindo seus respectivos desvios padrões.

Tabela 3: Valores médios da dureza, cloretos, alcalinidade e STD das amostras.

\begin{tabular}{|c|c|c|c|c|}
\hline $\begin{array}{c}\text { Poços } \\
\text { analisados }\end{array}$ & $\begin{array}{c}\text { Dureza } \\
\left(\mathrm{CaCO}_{3} / \mathrm{mg.L}^{-1}\right)\end{array}$ & $\begin{array}{l}\text { Cloretos } \\
(\mathrm{mg} / \mathrm{L})\end{array}$ & $\begin{array}{l}\text { Alcalinidade } \\
\quad(\mathrm{mg} / \mathrm{L})\end{array}$ & $\begin{array}{l}\text { STD } \\
(\mathrm{mg} / \mathrm{L})\end{array}$ \\
\hline Poço A & $436,38 \pm 0,173$ & $0,60 \pm 0,005$ & $86,0 \pm 0,057$ & $2,334 \pm 0,058$ \\
\hline Poço B & $409,56 \pm 0,050$ & $0,57 \pm 0,100$ & $100,0 \pm 0,100$ & $1,938 \pm 0,222$ \\
\hline Poço C & $424,38 \pm 0,026$ & $0,57 \pm 0,057$ & $72,0 \pm 0,058$ & $2,557 \pm 0,086$ \\
\hline Poço D & $401,56 \pm 0,115$ & $0,55 \pm 0,115$ & $86,0 \pm 0,057$ & $2,418 \pm 0,131$ \\
\hline VMP* & 500 mg.L $\mathrm{L}^{-1}$ & $250 \mathrm{mg} / \mathrm{L}$ & $\begin{array}{c}\text { Não } \\
\text { especificado }\end{array}$ & 1000 mg/L \\
\hline
\end{tabular}

Fonte: Dados da pesquisa, 2019. 
Tratando-se da dureza, as amostras apresentaram uma variação entre 401,56 e 436,3 mg. $\mathrm{L}^{-1}$ de $\mathrm{CaCO}_{3}$. Sendo assim, as amostras apresentam durezas totais que atendem a condição estabelecida pelo Ministério da Saúde. Em um estudo feito por Lima et al. (2017), os poços da cidade de TriunfoParaíba apresentaram variações de dureza total entre 78 a $646,5 \mathrm{mg} \cdot \mathrm{L}^{-1}$.

$O$ teor de cloretos das amostras, variam entre 0,55 e $0,60 \mathrm{mg} / \mathrm{L}$, estando de acordo com o valor máximo permitido. Segundo Silva et al. (2015), as águas subterrâneas da cidades de Cuité e Areial no interior da Paraíba, apresentaram baixos valores para o parâmetro cloretos, com valores variando de 2,49 a 16,89 $\mathrm{mg} / \mathrm{L}$.

A alcalinidade não se constitui em padrão de potabilidade, ficando este efeito limitado pelo valor do $\mathrm{pH}$. Além disso, não há um valor especificado pelo MS para este parâmetro. Entretanto, os valores correspondentes a alcalinidade das amostras foram baixos, variando entre 72,0 e $86,0 \mathrm{mg} / \mathrm{L}$.

A respeito dos sólidos totais dissolvidos das amostras, os valores apresentaram uma variação entre 1,938 e 2,557 mg/L, se adequando ao valor máximo permissível disponibilizado pelo MS.

\subsection{Concentração de Sódio e Potássio no fotômetro de chama}

O fotômetro de chama é um aparelho analítico usado para o estudo do espectro de emissão de certas substâncias. A fotometria de chama tem a vantagem de ser simples, rápida, de alta sensibilidade e de baixo consumo de amostra (QUIMIS, 2011).

De acordo com Lucas et al. (2014), o sódio é um dos elementos encontrado em maior abundância na Terra, sendo solúvel em água. Já o potássio é um elemento que está em baixas concentrações nas águas naturais, sendo a lixiviação das rochas a sua principal fonte natural. Portanto, a fonte antrópica é uma das suas fontes, visto que é um elemento utilizado na indústria e na agricultura (Zuin et al., 2009).

$\mathrm{Na}$ tabela 4, estão dispostos os valores obtidos a respeito da identificação de sódio e potássio nas amostras e seus respectivos desvios padrão. 
Tabela 4: Valores médios da identificação de sódio e potássio das amostras.

\begin{tabular}{|c|cc|}
\hline Poços analisados & Sódio $\left(\mathbf{N a}^{+}\right) \mathbf{( p p m )}$ & Potássio $\left.\left(\mathbf{K}^{+}\right) \mathbf{( p p m}\right)$ \\
\hline Poço A & $1377,0 \pm 4,68$ & $283,0 \pm 0,76$ \\
\hline Poço B & $1368,0 \pm 1,93$ & $400,6 \pm 0,15$ \\
\hline Poço C & $1356,0 \pm 4,80$ & $440,0 \pm 1,01$ \\
\hline Poço D & $1217,0 \pm 2,54$ & $237,0 \pm 0,37$ \\
\hline VMP* & $\mathbf{2 0 0} \mathbf{~ p p m}$ & Não especificado \\
\hline
\end{tabular}

Percebe-se que as amostras apresentaram diferentes concentrações de Sódio e Potássio no fotômetro de chama. Entretanto, todas as amostras apresentaram alto teor de Sódio, ultrapassando o valor máximo permitido pelo Ministério da Saúde de $200 \mathrm{mg} / \mathrm{L}$ (ppm). No estudo realizado por Silva et al. (2017) em águas subterrâneas do município de Taperoá-Paraíba, os resultados apresentaram altas concentrações de sódio, variando de 472 a $1145 \mathrm{mg} / \mathrm{L}$, não se adequando também ao padrão de potabilidade.

\subsection{Análise da composição química da cortiça no Espectrômetro de Fluorescência de Raios-X por Energia Dispersiva-EDX}

O Espectrômetro de Fluorescência de Raios-X por Energia Dispersiva_EDX é um aparelho utilizado para qualificar e quantificar os elementos químicos que compõem uma amostra. Nesta concepção, foi realizada a análise da cortiça in natura e após a adsorção por filtração para determinar os elementos químicos que fazem parte de sua composição. A tabela 5 , apresentam os dados obtidos neste tipo de análise.

No que se refere aos elementos constituintes da cortiça, o Cobre $(\mathrm{Cu})$ e o Ferro ( $\mathrm{Fe})$, tiveram uma melhor adsorção na cortiça com granulometria de $125 \mu \mathrm{m}$. O elemento Fósforo $(\mathrm{P})$ foi identificado e quantificado apenas na cortiça in natura, enquanto os elementos Hólmio (Ho) e Titânio (Ti) foram quantificados somente na cortiça após a adsorção.

\subsection{Análise das propriedades físico-químicas após a adsorção por filtração com o adsorvente natural da cortiça}

Com o intuito de melhorar as propriedades físico-químicas, em especial a diminuição do teor de sódio das amostras analisadas dos poços selecionados pertencentes ao município de Baraúna-Paraíba, foi utilizado como adsorvente natural a cortiça proveniente da rolha, derivada da árvore da espécie Sobreiro (Quercus Súber) em duas granulometrias, $250 \mu \mathrm{m}$ e $125 \mu \mathrm{m}$. 
Tabela 5: Composição química da cortiça in natura e após a adsorção por filtração.

\begin{tabular}{|c|c|c|c|c|}
\hline Elementos & $\begin{array}{c}\text { Cortiça } \\
\mathbf{2 5 0} \boldsymbol{\mu m} \\
\text { In natura \% }\end{array}$ & $\begin{array}{c}\text { Cortiça } \\
\mathbf{1 2 5} \boldsymbol{\mu m} \\
\text { In natura \% }\end{array}$ & $\begin{array}{c}\text { Cortiça } \\
\mathbf{2 5 0} \boldsymbol{\mu m} \text { após } \\
\text { adsorção \% }\end{array}$ & $\begin{array}{c}\text { Cortiça } \\
\mathbf{1 2 5} \boldsymbol{\mu m} \text { após } \\
\text { adsorção \% }\end{array}$ \\
\hline Cálcio $(\mathrm{Ca})$ & 40.798 & 39.796 & 71.841 & 73.154 \\
\hline Silício $(\mathrm{Si})$ & 6.230 & 9.057 & 7.732 & 9.157 \\
\hline Enxofre $(\mathrm{S})$ & 3.209 & 3.388 & 5.105 & 4.365 \\
\hline Manganês $(\mathrm{Mn})$ & 1.688 & 1.623 & 1.058 & 0.892 \\
\hline Ferro $(\mathrm{Fe})$ & 2.083 & 2.439 & 2.381 & 2.603 \\
\hline Fósforo $(P)$ & 1.220 & 1.240 & - & - \\
\hline Titânio $(\mathrm{Ti})$ & - & - & 0.614 & 0.964 \\
\hline Cobre $(\mathrm{Cu})$ & 0.781 & 0.760 & 0.850 & 0.863 \\
\hline Ósmio $(\mathrm{Os})$ & 0.722 & 0.542 & 0.702 & 0.646 \\
\hline Hólmio $(\mathrm{Ho})$ & - & - & 2.216 & 2.029 \\
\hline Zinco $(\mathrm{Zn})$ & 0.522 & 0.586 & 0.609 & 0.602 \\
\hline Bromo $(\mathrm{Br})$ & 0.267 & 0.225 & 0.346 & 0.263 \\
\hline & Fonte: Dados da pesquisa, 2019. & & \\
\hline
\end{tabular}

Durante o desenvolvimento da pesquisa, foi notável que o adsorvente natural utilizado (cortiça) apresentou-se ser eficiente na redução da alcalinidade e das concentrações de sódio e potássio das amostras, destacando-se principalmente a diminuição nos valores do teor de sódio que caracterizava as amostras como imprópria para o consumo humano, podendo assim ser utilizadas apenas para atividades primárias. No que se diz respeito ao $\mathrm{pH}$, dureza total, alcalinidade e teor de cloretos das amostras após a adsorção, foi perceptível a ocorrência de pequenas variações que caracterizam aumentos nestes parâmetros, porém ainda se apresentam dentro do solicitado pelo MS. Estes acontecimentos podem ter sido ocasionados pelas propriedades das matrizes assim como pelas propriedades do adsorvente utilizado, proporcionando interferências nos resultados da adsorção, cabe considerar que nem sempre o material atenderá de maneira eficaz como adsorvente em todos os parâmetros estudados devido a influência do efeito de matriz ( amostras).

As tabelas abaixo, apresentam os dados obtidos das amostras após o processo de adsorção por filtração.

De acordo com a tabela 6 , as amostras apresentaram pequenas variações de pH após a adsorção com a cortiça. Entretanto, a amostra do Poço 
D que teve a adsorção com a cortiça de granulometria $125 \mu \mathrm{m}$, não se adequou a faixa de $\mathrm{pH}$ estabelecida na Portaria n5/2017 do Ministério da Saúde.

Tabela 6 Valores médios do pH das amostras após a adsorção por filtração.

\begin{tabular}{|c|c|c|}
\hline Poços analisados & $\begin{array}{l}\text { Valores médios de pH } \\
\quad(\text { cortiça } 250 \mu \mathrm{m})\end{array}$ & $\begin{array}{l}\text { Valores médios de pH } \\
(\text { cortiça } 125 \mu \mathrm{m})\end{array}$ \\
\hline Poço A & $6,46 \pm 0,05$ & $6,61 \pm 0,03$ \\
\hline Poço D & $6,04 \pm 0,03$ & $5,40 \pm 0,03$ \\
\hline VMP* & \multicolumn{2}{|c|}{6,0 a 9,5} \\
\hline
\end{tabular}

$\mathrm{Na}$ determinação da dureza total, a cortiça provocou um pequeno aumento nos valores para este parâmetro, como mostrado na tabela 7 abaixo. Apesar do aumento, as amostras variaram entre 423,6 a 446,4 $\mathrm{CaCO}_{3} / \mathrm{mg}^{-\mathrm{L}^{-1}}$, continuando de acordo com o valor máximo permitido, como pode ser observado na tabela 7 abaixo.

Tabela 7: Valores médios da dureza total das amostras após a adsorção por filtração.

\begin{tabular}{|c|c|c|}
\hline Poços analisados & $\begin{array}{c}\text { Dureza }\left(\mathrm{CaCO}_{\mathbf{3}} / \mathbf{m g . L}^{-\mathbf{1}}\right) \\
(\mathbf{c o r t i c ̧ a ~} \mathbf{2 5 0} \boldsymbol{\mu m})\end{array}$ & $\begin{array}{c}\text { Dureza }\left(\mathrm{CaCO}_{\mathbf{3}} / \mathbf{m g . L}^{\mathbf{- 1}}\right) \\
(\text { cortiça 125 } \boldsymbol{\mu m})\end{array}$ \\
\hline Poço A & $446,4 \pm 0,15$ & $423,6 \pm 0,10$ \\
\hline Poço D & $446,4 \pm 0,05$ & $446,4 \pm 0,08$ \\
\hline VMP* & \multicolumn{2}{|c|}{$\mathbf{5 0 0} \mathbf{C a C O}_{\mathbf{3}} / \mathbf{m g . L}^{\mathbf{- 1}}$} \\
\hline
\end{tabular}

Na tabela 8 é possível perceber os dados obtidos na análise do teor de cloretos das amostras. Após a adsorção, as amostras apresentaram pequenas variações e aumentos nos teores de cloretos, entretanto, nenhuma das amostras ultrapassaram o valor máximo estabelecido na Portaria ํำ/2017 do Ministério da Saúde.

Tabela 8: Valores médios de cloretos após a adsorção por filtração.

\begin{tabular}{|c|c|c|}
\hline Poços analisados & $\begin{array}{c}\text { Cloretos }(\mathbf{m g} / \mathbf{L}) \\
\text { (cortiça } \mathbf{2 5 0} \boldsymbol{\mu m})\end{array}$ & $\begin{array}{c}\text { Cloretos } \mathbf{( m g} / \mathbf{L}) \\
\text { (cortiça } \mathbf{1 2 5} \boldsymbol{\mu m})\end{array}$ \\
\hline Poço A & $0,632 \pm 0,10$ & $0,848 \pm 0,10$ \\
\hline Poço D & $0,776 \pm 0,09$ & $0,728 \pm 0,15$ \\
\hline VMP* & $\mathbf{2 5 0} \mathbf{~ m g . L}^{-\mathbf{1}}$ & \\
\hline
\end{tabular}

A tabela 9, apresenta os dados obtidos à respeito da alcalinidade das amostras após o tratamento com a cortiça. Foi possível observar que após a adsorção, houve uma redução na alcalinidade das amostras. Entretanto, não há um valor máximo estabelecido na Portaria n5/2017 do Ministério da Saúde que indique uma alcalinidade ideal. 
Tabela 9: Valores médios da alcalinidade após a adsorção por filtração.

\begin{tabular}{c|cc|c|} 
Poços analisados & $\begin{array}{c}\text { Alcalinidade }(\mathbf{m g} / \mathbf{L}) \\
\text { (cortiça } \mathbf{2 5 0} \boldsymbol{\mu m})\end{array}$ & $\begin{array}{c}\text { Alcalinidade }(\mathbf{m g} / \mathbf{L}) \\
\text { (cortiça 125 } \mathbf{~ m m})\end{array}$ \\
\hline Poço A & $15,0 \pm 0,05$ & $13,0 \pm 0,05$ \\
\hline Poço D & $15,0 \pm 0,08$ & $0,728 \pm 0,02$ \\
\hline VMP* & \multicolumn{2}{|c|}{ Não especificado } \\
\hline
\end{tabular}

Na tabela 10, estão inseridos os dados obtidos da turbidez das amostras após a adsorção. Foi possível observar que após a adsorção, houve um grande aumento na turbidez das amostras, ultrapassando o valor máximo estabelecido na Portaria ํㅗ 5/2017 do Ministério da Saúde de 5,0 NTU, com exceção apenas da amostra $A$ adsorvida com a cortiça de $125 \mu \mathrm{m}$ que se manteve dentro do padrão estabelecido. A ocorrência deste aumento pode ter sido resultante da coloração obtida após o processo de adsorção, uma vez que durante 0 desenvolvimento da técnica de tratamento foi possível perceber que as amostras obtiveram uma coloração turva e amarelada após o contato com o adsorvente, mesmo com a realização da lavagem do material, provavelmente esta coloração tenha sido liberada por substâncias que fazem parte da composição química da cortiça. Sendo assim, pode-se constatar que a cortiça não apresentou eficiência significativa na redução da turbidez das amostras analisadas, quando se refere a amostra do poço $D$.

Tabela 10: Valores médios da turbidez após a adsorção por filtração.

\begin{tabular}{|c|c|c|}
\hline Poços analisados & $\begin{array}{l}\text { Turbidez (NTU) } \\
\text { (cortiça } 250 \mu \mathrm{m})\end{array}$ & $\begin{array}{l}\text { Turbidez (NTU) } \\
\text { (cortiça } 125 \mu \mathrm{m})\end{array}$ \\
\hline Poço A & $10,5 \pm 0,36$ & $3,78 \pm 0,17$ \\
\hline Poço D & $16,1 \pm 0,44$ & $9,23 \pm 0,05$ \\
\hline VMP* & & \\
\hline
\end{tabular}
concentrações de Sódio e Potássio após o tratamento com a cortiça nas águas subterrâneas de Baraúna-Paraíba.

Tabela 11: Valores médios da concentração de sódio após a adsorção com a cortiça.

\begin{tabular}{|c|c|c|}
\hline Poços analisados & $\begin{array}{l}\text { Sódio }\left(\mathrm{Na}^{+}\right) \text {- ppm } \\
\text { (cortiça } 250 \mu \mathrm{m})\end{array}$ & $\begin{array}{l}\text { Sódio }\left(\mathrm{Na}^{+}\right) \text {- ppm } \\
(\text { cortiça } 125 \mu \mathrm{m})\end{array}$ \\
\hline Poço A & $293,84 \pm 4,79$ & $297,84 \pm 2,40$ \\
\hline Poço D & $298,84 \pm 3,87$ & $285,68 \pm 1,92$ \\
\hline VMP* & \\
\hline
\end{tabular}


Antes da adsorção, as amostras apresentavam altas concentrações de Sódio, ultrapassando o valor de 1000 ppm, cada. Com o tratamento utilizando a cortiça como adsorvente natural foi possível perceber que houve uma diminuição significativa nas concentrações de Sódio das amostras, o que indica que a cortiça tornou-se eficiente como adsorvente para este parâmetro analisado, os valores variam entre $285,68 \pm 1,92$ e $298,84 \pm 3,87 \mathrm{ppm}$. Entretanto, mesmo apresentando esta redução, as amostras ainda continuam apresentando teores acima do valor máximo permitido pelo Ministério da Saúde (200ppm).

Tabela 12: Valores médios da concentração de potássio após a adsorção por filtração.

\begin{tabular}{|c|c|c|}
\hline Poços analisados & $\begin{array}{c}\text { Potássio }\left(\mathbf{K}^{+}\right) \mathbf{- ~} \mathbf{~ p p m} \\
\text { (cortiça } \mathbf{2 5 0} \boldsymbol{\mu m})\end{array}$ & $\begin{array}{c}\text { Potássio }\left(\mathbf{K}^{+}\right) \mathbf{~} \mathbf{~ p p m} \\
(\mathbf{c o r t i c ̧ a ~ 1 2 5} \boldsymbol{\mu m})\end{array}$ \\
\hline Poço A & $114,40 \pm 1,94$ & $122,00 \pm 0,62$ \\
\hline Poço D & $103,84 \pm 0,64$ & $101,36 \pm 1,72$ \\
\hline VMP* & \multicolumn{2}{|c|}{ Não especificado } \\
\hline \multicolumn{3}{|c|}{ Fonte: Dados da pesquisa, 2019. } \\
\hline
\end{tabular}

Observa-se que tanto antes como após o processo de adsorção as concentrações de Potássio nas amostras foram menores do que as concentrações de sódio. As concentrações de Potássio obtidas após o tratamento variam de 101,36 $\pm 1,72$ e 103,84 \pm 0,64 ppm, como mostrado na tabela 12 , sendo possível perceber que a cortiça apresentou a capacidade de reduzir as concentrações deste elemento.

\section{Conclusão}

Portanto, com a realização do estudo foi possível verificar a eficiência da cortiça como adsorvente natural, assim como da técnica de adsorção por filtração, sendo constatado uma redução significativa nas concentrações de Sódio, onde as concentrações antes do tratamento com o adsorvente eram elevadas. Entretanto, mesmo apresentando algumas reduções nos parâmetros com o uso da cortiça, as amostras analisadas ainda continuam imprópria para o consumo, devido as concentrações de Sódio e a turbidez das amostras ultrapassarem o valor máximo permitido pelo Ministério da Saúde.

Além disso, verificou-se que a granulometria do adsorvente interfere diretamente nos resultados, onde pode-se observar que para o poço $A$, a 
cortiça que mostrou melhores resultados no que se diz respeito a redução dos parâmetros foi a cortiça de $250 \mu \mathrm{m}$, enquanto que para o poço $\mathrm{D}$ foi a cortiça de cortiça $125 \mu \mathrm{m}$.

Cabe destacar que a metodologia adotada no estudo, adsorção por filtração, é empregada comumente na área de tratamento de águas e apresenta a finalidade de reduzir à presença de metais tóxicos e outros poluentes, mas, os resultados obtidos com a utilização dessa técnica dependem do tipo de adsorvente utilizado e das propriedades das matrizes.

O presente estudo torna-se relevante por fornecer informações sobre a qualidade das águas subterrâneas do município de Baraúna-PB, assim como da composição química da cortiça in natura e sua eficácia como adsorvente natural.

\section{Referências}

APHA - AWWA - WEF. American Public Health Association; American Water Work Association; Water Environment Federation. Standard Methods for the Examination of Water and Wastewater. Rodger B. BAIRD, Andrew D. CLESCERI; Amer. Public Health Assn: Washington, 22 eds. 2012.

BORGES, Mauricio José; GALBIATTI, João Antonio; FERRAUDO, Antonio Sergio. Monitoramento da qualidade hídrica e eficiência de interceptores de esgotos em cursos d'água urbanos da Bacia Hidrográfica do Córrego Jaboticabal. Revista Brasileira de Recursos Hídricos, v.8, n.2, p.161-171, 2003.

BRASIL. Ministério da Saúde. PORTARIA DE CONSOLIDAÇÃO no. 5/2017. Dispõe sobre à " Consolidação das normas sobre as ações e os serviços de saúde do Sistema Único de Saúde". Anexo XX - Do controle e da Vigilância da Qualidade da Água para Consumo Humano e seu Padrão de Portabilidade (origem. PRTMS/GM 2914/2011). Brasília, 2017. Disponível em: <http://bvsms.saude.gov.br/bvs/saudelegis/gm/2017/pro0005_03_10_2017.htm> . Acesso em 17 de setembro de 2019.

BRASIL. Secretaria de Vigilância em Saúde. Vigilância e controle da qualidade da água para o consumo. Brasília, 2006. 212 p. 
BRASIL. Ministério de Minas e Energia. Projeto cadastro de fontes de abastecimento por água subterrânea - Diagnóstico do munícipio de Baraúna. Recife, 2005. 19 p.

CASALI, Carlos Alberto. Qualidade da água para consumo humano ofertada em escolas e comunidades rurais da região central do Rio Grande do Sul. 2008. $172 f$. Dissertação (Mestrado em Ciência do Solo) - Universidade Federal de Santa Maria, Santa Maria, RS, 2008.

COSTA, Cecília Leite, et al. Avaliação da qualidade das águas subterrâneas em poços do estado do Ceará, Brasil. Semana: Ciências Biológicas e da Saúde, v. 33, n. 2, 171-180, 2012.

COSTA, Maria de Lurdes Belgas. Caracterização das propriedades físicas, mecânicas e térmicas de betões com incorporação de cortiça. 2011. 331p. Tese (Doutorado em Engenharia Civil). Universidade de Coimbra, Coimbra, 2011.

FUNASA, Fundação Nacional de Saúde. Manual de Controle da Qualidade da Água para Técnicos que Trabalham em ETAS. Brasília: 2014. 112 p.

FUNASA, Fundação Nacional de Saúde. Manual prático de análise de água. 4a edição. Brasília, 2013.

IBGE. Instituto Brasileiro de Geografia e Estatística. 2010. Disponível em: $<$ https://www.ibge.gov.br/cidades-e-estados/pb/barauna.html>. Acesso em: 5 de junho de 2020.

LIMA, Santana Lívia de, et al. Qualidade das águas de poços públicos da zona urbana do município de Triunfo-PB. Congresso Técnico Científico da Engenharia e da Agronomia - CONTECC. Belém/PA, 2017.

LUCAS, Ariovaldo Antonio Tadeu, et al. Qualidade da água no riacho Jacaré, Sergipe e Brasil usada para irrigação. Revista Brasileira de Agricultura Irrigada, v. 8, n. 2, p. 98-105, 2014. 
MACHADO, Maria Clara Bezerra Teixeira, et al. Caracterização físico-química das águas subterrâneas de Paraíso do Tocantins. In: VIII CONGRESSO BRASILEIRO DE GESTÃO AMBIENTAL. Campo Grande/MS, 2017.

MEDEIROS, Raquel da Silva. Impactos de medidas de conservação de água na área rural: uma avaliação do programa produtor de águas na recepção do produtor. 2016. 45 f. Trabalho de Conclusão de Curso (Graduação em Gestão Ambiental). Universidade de Brasília, Distrito Federal, DF, 2016.

MENEZES, José Carlos; MACHADO, Cristyano Ayres; NASCIMENTO, Robério Oliveira. Uma análise científica da água. V Colóquio Internacional "Educação e contemporaneidade". São Cristóvão, 2011.

QUIMIS. Aparelhos científico LDTA. Manual de Instruções do fotômetro de chama Q498M. Diadema/SP, 2011.

SANTOS, Renata de Souza; MOHR, Tainara. Saúde e qualidade da água: Análises microbiológicas e físico-químicas em águas subterrâneas. Revista Contexto e Saúde, v. 13 , n. 24/25, p. 46-53, abr, 2014.

SILVA, Ronaldo de Araújo, et al. Caracterização físico-química das águas dos poços tubulares localizados nas cidades de Cuité e Areial no semiárido paraibano. 5을 Simpósio de Segurança Alimentar: Alimentação e Saúde. Bento Gonçalves - RS, 2015.

SILVA, Veridiana Alves da.; MEDEIROS, Maria Jamylle Santos de.; MEDEIROS, Rosália Severo de. Aspectos físico-químicos da água subterrânea consumida no município de Taperoá - PB. II Congresso Internacional da Diversidade do Semiárido - II CONIDIS. Realize Eventos, 2017.

ZUIN, Vânia Gomes.; IORIATTI, Maria Cecília. S.; MATHEUS, Carlos Eduardo. O emprego de parâmetros físicos e químicos para a avaliação da qualidade de águas naturais: uma proposta para a educação química e ambiental na perspectiva CTSA. Química Nova na Escola, v. 31. 2009. 
EDUCAÇÃO CIÊNCIA E SAÚDE | http://dx.doi.org/10.20438/ecs.v7i1.240

\section{Agradecimentos}

Ao Conselho Nacional de Desenvolvimento Científico e Tecnológico - CNPq pelo financiamento da bolsa PIBIC/Propex- UFCG. 